\title{
Cuando las "obreras del pensamiento" escriben de amor: Juana Manso, Carlota Garrido de la Peña y Mercedes Práxedes Muñoz
}

\author{
Beatriz FERRÚS ANTÓN \\ Universitat Autònoma de Barcelona
}

\begin{abstract}
RESUMEN
Clorinda Matto de Turner escribió "Las obreras del pensamiento en la América del Sur". Este texto crea un canon de mujeres. Juana Manso, Carlota Garrido de la Peña y Margarita Práxedes Muñoz son nombres que ella cita. Estas tres autoras escribieron novelas de folletín, donde analizan el papel de la mujer en su época. El modelo del "ángel del hogar" es siempre una referente, que propondrán rescribir. Estos folletines aparecerán cargados de las ambivalencias y paradojas fruto de un tiempo de tránsito y proto-feminismo.
\end{abstract}

Palabras clave: Juana Manso, Carlota Garrido de la Peña, Margarira Práxedes Muñoz, ángel del hogar, mujer, folletín.

When "obreras del pensamiento" write of love: Juana Manso, Carlota Garrido de la Peña, Margarira Práxedes Muñoz

\begin{abstract}
Clorinda Matto de Turner wrote "Las obreras del pensamiento en la América del Sur", this text created a women's canon. Juan Manso, Carlota Garrido de la Peña y Margarita Práxedes Muñoz are writers that she cited. They wrote serialized novel, where they analysed the women's role in their time. The model of domestic angel was the reference. They proposed it's re-writing. These novels are loaded with ambiguities and paradoxes.
\end{abstract}

Key words: Juana Manso, Carlota Garrido de la Peña, Margarita Práxedes Muñoz, Domestic angel, Woman, Serialized novel.

SUMARIO: 1. Juana Manso y La familia del Comendador. 2. Carlota Garrido de la Peña, "corazón argentino". 3. Margarita Práxedes Múñoz: amor y ciencia. 4. Cuando las obreras del pensamiento escriben de amor

El 14 de Diciembre de 1895 Clorinda Matto de Turner lee en el Ateneo de Buenos Aires la conferencia "Las obreras del pensamiento en América del Sur", texto que constituye una cartografía de la formación de la figura de la escritora profesional en América Latina. Matto de Turner recorre uno a uno los países del 
continente consignando los nombres de sus escritoras (periodistas, poetas, narradoras, dramaturgas etc.). El extenso listado habla de un fenómeno imparable en la segunda mitad del siglo XIX: la profesionalización de la mujer invade el mundo de las letras, creando imprevistos efectos ${ }^{1}$.

Este suceso se anticipaba casi una década antes en América y sus mujeres (1886) de Emilia Serrano, quien retrata no sólo la progresiva incorporación de las mujeres americanas al mundo profesional, sino también las redes de apoyo que entre las primeras feministas se irán trazando a uno y otro lado del océano. De igual forma, cuando Clorinda Matto de Turner escribe Viaje de recreo (1909), a diferencia de lo que el nombre de su texto indica, no plantea tanto el relato de su periplo como la descripción de los espacios visitados, sino como un listado de nombres de mujeres, que, en tanto, destacadas escritoras, científicas, pedagogas o simplemente feministas ayudan a transformar el sentido del mundo que se recorre: "Me refiero a las mujeres que escriben, verdaderas heroínas que, luchan, día a día, hora tras hora, para producir el libro, el folleto, el periódico, encarnados en el ideal del progreso femenino" (Matto, 1909: 252).

Es decir, muchas de esas recién nacidas "obreras del pensamiento" harían de su obra un espacio de reflexión sobre las condiciones que permitieron la consolidación de su figura profesional, re-creando en sus textos un "canon" (de mujeres) que no por necesario deja de ser excéntrico. Así, por ejemplo, los libros misceláneos de Juana Manuela Gorriti o Clorinda Matto de Turner recogen "miniaturas", retratos o semblanzas de poetas, narradoras o intelectuales, que merecen ser destacadas entre sus contemporáneos, como ejercicio de visibilización del trabajo letrado de la mujer. La misma Matto explicita, de este modo, el origen de los materiales allí reunidos:

Hoy lo entrego a la prensa recogiendo en un solo volumen las hojas que he derramado casi diariamente en faena periodística; unas que son fruto de la labor paciente en la observación y la historia; otras, como haz de páginas esparcidas por el viento huracanado en las horas sin descanso de la viajera, de proscrita, de operaria en la factoría de los grandes pueblos donde hay que ganarse el pan a peso de oro. De ahí deriva la necesidad de separarlas por partes; ésta es la razón por las cual las titulo: Boreales, Miniaturas y Porcelanas... nombres y fechas que más tarde han de ser buscados por quienes de la literatura se ocupen de nuestro naciente taller americano. (Matto de Turner 1902: II)

El apogeo de la prensa en el continente durante la segunda mitad del XIX permite la profesionalización del escritor(a) y sólo el tránsito por sus páginas

${ }^{1}$ Esta investigación se ha desarrollado dentro del proyecto: Las primeras escritoras $y$ artistas profesionales. Redes de mujeres y mitologías de progreso (Fondo críticodocumental España-Estados Unidos), financiado por el Instituto Franklin. 
posibilita, en ocasiones, el reconocimiento que dará acceso al mundo editorial. Por otra parte, al igual que sucede en Europa, hay un género que despierta la voracidad y el deseo de numerosos lectores: el folletín, que, haciendo del amor, muchas veces, el eje de su relato, imagina modelos de femineidad, masculinidad, ciudadanía etc. que habrían de modelar la conciencia de miles de lectores. No sólo en los periódicos, sino también en cientos de ediciones populares que los continuaron, sus historias recorren América Latina durante fines del XIX y principios del XX dejando a su paso indelebles huellas:

Estos 'novelines', como se los denominaba en alguna literatura de la época, responden a un fenómeno socio-ideológico: la necesidad de ficción; de formas, tópicos y figuras sobre las que trabaja el imaginario colectivo y que, al mismo tiempo, lo constituyen (Sarlo 39)

La cuestión femenina aparece en estas narraciones sólo como cuestión de los afectos. Sin embargo, el lugar de la mujer es exaltado narrativamente, porque se la presenta como señora (aunque también esclava) de pasiones arrolladoras: rodeado por las solicitudes del pasado amante, el personaje femenino es objeto de atenciones y cuidados. Una vez que se ha fijado su lugar se lo convierte en objeto amado dulce o apasionadamente, aunque también en objeto sobre el que se ejerce la crueldad o el abandono. (Sarlo 22)

No obstante, ¿qué sucede cuando son las recién nacidas obreras del pensamiento quienes escriben de amor? Doris Sommer, en su ensayo ya clásico sobre el género, afirma que:

Las novelas románticas se desarrollaron mano a mano con la historia patriótica de América Latina. Juntas despertaron un ferviente deseo de felicidad doméstica que se desbordó en sueños de prosperidad nacional materializados en proyectos de construcción de naciones que invistieron a las pasiones privadas con objetivos públicos. (Sommer 23)

A pesar de que las jóvenes lectoras, que irresistiblemente fueron atraídas por este tipo de novelas sentimentales, se educaban en las virtudes restrictivas de la maternidad patriótica... estos libros habrían de complicar, a mediados de siglo, nuestra noción del ideal femenino (Sommer 33)

Como folletín, novela sentimental o novelín, desde mediados del siglo XIX hasta bien entrado el siglo XX, con estética romántica, tadorromántica o modernista, las historias de amor rescribirían, una y otra vez, con pequeñas variantes, unos mismos modelos de mujer. ¿Cómo enfrentaron las escritoras estos modelos? ¿Los reforzaron o los cuestionaron? ¿Hubo una alternativa a la omnipresente madre de la nación, ángel del hogar al servicio de la patria?

Mary Louise Pratt en su artículo "No me interrumpas: las mujeres y el ensayo latinoamericano" (Pratt) distingue dos tradiciones diferentes, que convivieron de 
forma paralela y que desarrollaron estrategias y fórmulas propias de lectura: el "ensayo de identidad" de los intelectuales criollos y el "ensayo de género", como tradición alternativa creada por mujeres. El segundo impugna al primero, denunciando implícitamente sus exclusiones; al tiempo que imagina nuevas formas de existencia y ciudadanía para las mujeres. Entendemos que esta misma dualidad puede apreciarse en el caso de narrativa, pues si las grandes novelas nacionales corren en paralelo al "ensayo de identidad", el folletín escrito por mujeres ficcionaliza muchas de las preguntas del "ensayo de género".

Estas páginas intentarán responder a estas preguntas, aunque las respuestas jamás serán sencillas; ya que la complejidad de un tiempo de tránsito, de continuas transformaciones para la "historia de las mujeres", dará lugar a múltiples ambivalencias y paradojas.

Para ello analizaremos la obra de tres de esas "obreras del pensamiento", Juana Manso, conocida por sus vínculos con Juana Manuela Gorriti, Carlota Garrido de la Peña y Mercedes Práxedes Múñoz, ambos nombres hoy casi olvidados. La elección de este corpus no resulta azarosa, sino que responde a una sugerente y plural manera de enfrentar el vínculo amor/matrimonio, así como de rescribir el modelo del "ángel del hogar" de larga andadura en las narrativas del XIX y principios del $\mathrm{XX}$.

\section{Juana Manso y La familia del Comendador}

Juan Manso (1819-1875) fue una activista feminista, pedagoga y escritora, que reivindicó los derechos de las mujeres en Argentina, a partir de su actividad pública, pero también de los contra-modelos hegemónicos suministrados en sus ficciones. Su biografía suele entrelazarse con la de Juana Manuela Gorriti, tal y como sucede en aquella que precede a Misceláneas. Leyendas, juicios, pensamientos, discursos, impresiones de viaje y descripciones americanas de Gorriti, donde ésta se entrevista con Manso poco antes de su muerte; al tiempo que recoge también su testigo. Los biógrafos de ambas parecen fascinados por un saber que se transmite de mujer a mujer, por la continuidad de un linaje, fascinación que no deja de tener un significado ambiguo.

Sobre ella dice Clorinda Matto en "Las obreras del pensamiento":

y la señora Juana Manso, cuya labor sobre educación fue tan fecunda en resultados, son las mujeres argentinas que ya, entregaron a Dios su espíritu abrillantado por la ilustración y purificado en el crisol del heroísmo, porque ellas, más que las de la presente generación, tuvieron que sostener lucha tenaz contra las preocupaciones, pues lo que en Europa y América del Norte constituye una profesión honrosa y lucrativa, América del Sur es casi un defecto. (Matto, 1902: 253) 
Entre sus obras de ficción, aparecidas en folletín, encontramos Los misterios del Plata en O Jornal das Senhoras desde el 4 de enero de 1852 hasta el 2 de junio del mismo año, que, después, vería la luz en El Inválido Argentino; además de La familia del Comendador, editada en el Álbum de señoritas de manera incompleta por el cese de la publicación, entre el 1 de enero y el 17 de febrero de $1854^{2}$, que más tarde se editaría en libro de forma completa.

Es este segundo folletín el que nos interesa aquí, puesto que es la relación amor/matrimonio aquella que constituye el eje de la trama. En la novela se enfrentan dos cosmovisiones, que afectan al modo en que se articulan no sólo las relaciones de género, sino también raciales, incluso de clase.

La historia es muy sencilla, el matrimonio formado por el Comendador y su esposa, bajo la influencia de la madre de éste, decide casar a sus hijos todavía muy jóvenes. El modelo que escogen para ellos es el suyo propio, que aparece cifrado en la descripción del mismo Comendador con la que comienza el relato:

Frívolo y ligero, le son desconocidas las afecciones profundas, nunca supo lo que era la voluntad propia; tomo siempre el placer, por el amor y fuera de sus grandes ojos negros, de sus sedosos bigotitos y de sus bellos cabellos castaños, pero le importaba el resto. Se había casado con su prima Carolina, porque su madre así le ordenara, y él había obedecido, reservándose el derecho de seducir a las mucamas de su mujer y a todas las jóvenes de su hacienda, que encontraba en su camino; de estos inocentes pasatiempos resultaban siempre una infeliz mulatillas, muerta a azotes por orden de su ama, ya una negrita vendida encinta para alguna provincia distante etc. (Manso 29)

Para el Comendador su matrimonio no es más que un contrato económico, que, además, deriva en abusos hacia las mujeres de otras razas que conviven con él, le pertenecen y carecen de cualquier posibilidad de defensa. Por eso, lo que espera de su propia hija Gabriela es que se case son su tío, no sólo mucho mayor que ella, sino demente, como consecuencia de haber sido privado del amor de su vida; quien, además, ha construido una unión de hecho con la mulata Camila de la que han nacido varios hijos. A partir de aquí, la trama principal de la novela es aquella protagonizada por Gabriela, que luchará por casarse por amor y por huir de un destino impuesto.

La ironía destructiva con la que Manso retrata al Comendador se cierne sobre todos aquellos protagonistas de la historia que tratan de oponerse al deseo de la joven, dispuesta a ser dueña de su vida, aún a costa de renunciar a cualquier

${ }^{2}$ La web http://www.juanamanso.org/2010/06/obras.html resulta una excelente herramienta de consulta sobre la autora, a ella debemos muchos datos reflejados en nuestro trabajo, así como la posibilidad de acceso a diferentes textos de Juana Manso. 
privilegio de clase. Pocas heroínas de folletín se fugan de casa decididas a emprender una vida en libertad.

Gabriela se distingue de las heroínas de las "novelas nacionales" porque, pese a encarnar un modelo de domesticidad angélica, es capaz de convertir su deseo en una fuerza transformadora, que no sólo cambiará su destino, sino el de aquellos que la rodean. Camila, la mulata unida a su tío, reivindicará también los derechos nacidos de su unión, como esposa y como madre, logrando una restitución, que no sólo rescribe su condición mujer, sino también su adscripción racial. Al final de la novela Camila y sus hijos, en especial Mauricio, que se convertirá en heredero de la fortuna de su padre y se unirá a su prima Mariquita, pese a su sangre mezclada. La novela no sólo denuncia e impugna la sumisión social de la mujer, sino también de mulatos y esclavos.

La presencia de negros y mulatos, esclavos o no, en el folletín, así como personajes indígenas, con protagonismo en la trama principal, aunque no es una constante del género, sí aparece en un número significativo de éstos, como respuesta a la realidad étnica del continente. Entre sus casos más conocidos está $S a b$ de Gertrudis Gómez de Avellaneda, donde esclavos y mujeres acaban equiparándose en un gesto altamente revolucionario, o Aves sin nido de Clorinda Matto, que da una respuesta muy diferente al "blanquear" a la protagonista indígena e integrarla, sin alusión a su diferencia o a sus orígenes, en su familia de adopción, criolla y de buena posición económica.

Ante la pregunta dónde ubicar al otro (o a la otra), dentro del proyecto nacional criollo, podemos encontrar tres posibilidades: a) la de su exclusión, que suele justificarse desde el malditismo de la alteridad, el otro es el malvado, antagonista de la trama novelesca, b) la del borramiento de la diferencia, la asimilación al yo, como sucede en Aves sin nido, c) la aceptación de la diferencia, pero sin superar la posición de subalternidad que la acompaña, tal es el caso de Sab.

No obstante, la fórmula de La familia del Comendador es mucho más atrevida, puesto que Mauricio consigue convertirse en heredero de la fortuna y del linaje sin renunciar a su diferencia; todavía más, hace de ella una política: su primer gesto tras ser reconocido como hijo legítimo es liberar a los esclavos de su padre. El folletín "de género" se muestra contestatario ante el modelo de la novela nacional.

\section{Carlota Garrido de la Peña, "corazón argentino"}

Clorinda Matto de Turner en "Las obreras del pensamiento" sólo cita a Carlota Garrido de la Peña (1870-1958) entre aquellos nombres que "completan" el parnaso argentino, donde Juana Manuela Gorriti, Eduarda Masilla o Juana Manso ocupan una posición de mayor prestigio:

Los nombres que he mencionado bastarían para la gloria literaria de un pueblo; no obstante, aún tengo otros que agregar: Ana Pintos, que tan galanamente maneja el idioma, escondida tras el seudónimo de Amelia Palma; Amalia Solano, 
de las nutridas revistas; Carota Garrido de la Peña, autora de las novelas Mundana y Tila; María Emilia Passicót, Eufrasia Cabral, Aquilina Vidal de Bruss, María [254] E. Cardero, Adela A. Quiroga, Isabel Coronado, María Luisa Garay, Elena Jurado, María Brown, Arnold de González, Benita Campos, Elia M. Martínez, Yole Zolezzi, Macedonia Amavet, C. Espinosa, la señora de Funes y algunas otras que tal vez no he alcanzado a conocer, son, pues, las que hoy forman la legión de honor en la patria de Alberdi y de Sarmiento, con la particularidad de que las más de ellas son de provincias, muy pocas de esta gran Buenos Aires, con propiedad llamada la Nueva York del Sur. (Matto de Turner, 1902. 254)

Esta "ubicación secundaria" es la misma que parece haberle reservado la bibliografía crítica, pues son escasas las referencias que podemos encontrar sobre la autora. Nacida en Mendoza, fue de muy niña a vivir a Santa Fe, donde transcurriría su vida. Allí fundó en 1895 la revista El Pensamiento. Semanario de lecturas amenas, costumbres, asuntos religiosos y sociales, crónicas de salón y de modas, bibliografía, etc., etc., que habría de escandalizar al estar dirigida por una mujer, incorporándose a una larga nómina de autoras que tratarían de fundar y dirigir sus propias publicaciones. Volvería a tratar de probar suerte en 1902, junto a Carolina Freire de James, con la Revista Argentina, que duró tres años.

Se dedicó a la pedagogía, el periodismo y la literatura, como muchas de sus contemporáneas. Cuatro son las obras que hemos seleccionado para el análisis que nos ocupa: Reminiscencias (1888), Corazón Argentino. Diario de un niño, reeditada por cuarta vez en 1921 y Como en la vida/Mar sin riberas, novelas breves, reeditadas en 1917, publicadas conjuntamente en un mismo volumen, que llevan el subtítulo de "Novela de costumbres argentinas". Como veremos, estos textos plantean modos divergentes de imaginar a la mujer, que no siempre son fáciles de conciliar.

Moira Cristiá (2009) en "Entre tradición e innovación. Representaciones femeninas en otra modernidad periférica (Rosario, 1922-1924)" estudia la presencia femenina en Semana Gráfica, semanario publicado en Rosario entre 1922-1924, donde habrían de escribir Gabriela Mistral o Alfonsina Storni. Sobre la participación en el mismo de Carlota Garrido recoge algunas de sus afirmaciones, retratándola como una mujer de ideología fuertemente conservadora:

Por su parte, Carlota Garrido de la Peña, responsable de la sección "Temas de la sociedad. (Entre nosotras)" - posteriormente denominada "Temas femeninos (entre nosotras)" - es presentada por la dirección, el día del lanzamiento de su sección, como una conocida escritora muy apreciada por su producción y por “...una acentuada tendencia religiosa, ello no es un defecto sino virtud, que reafirma su fe y dice mucho de su sinceridad...”. Esta descripción concuerda con su actitud reaccionaria hacia las nuevas actitudes femeninas y su intención de reforzar valores como el pudor, la sencillez, la pureza, la fe religiosa y el patriotismo. (Cristiá) 
¿Es esta misma ideología la autora convoca en su narrativa de ficción? Corazón Argentino. Diario de un niño recoge una "Advertencia de la primera edición", donde la autora afirma:

Sin pretender haber escrito un libro como el D'Amicis (Corazón), pero, lo confieso, habiendo seguido modestamente su huella... Lo ofrezco a mis colegas los maestros de escuela... pues pienso que la misión más alta y excelente que puede realizar un educador que quiere servir a su país, es orientar hacia el bien el pensamiento y el corazón de los ciudadanos y el de las madres del porvenir. (Garrido de la Peña 1921)

Ciudadanos vs. madres del porvenir, sujetos complementarios, pero dispares, con diferente función social, según la ideología más conservadora del siglo XIX. Moira Cristiá (2009) glosa de este modo dos textos de la autora para Semana Gráfica "Los enervantes" y "Patriotismo de las mujeres", que parecen coincidir con "Advertencia":

En tanto la mujer es considerada bastión moral, la insistencia en proteger a las más jóvenes y advertirlas de la corrupción que las acecha se basa en la premisa "en cada niña hay una madre futura" (Garrido De La Peña, Carlota, "Los enervantes", SG, $\left.\mathrm{n}^{\circ} 36,17 / 05 / 1923\right)$. No basta con reafirmarlas en su rol de educadoras - como madres y maestras - el campo de acción femenino se amplía a la sensibilidad en general y a la solidaridad, legitimando actividades para salvaguardar a los desposeídos. Como "madres" de la sociedad, los círculos de beneficencia de "señoras conocidas" son ponderados en la revista anunciando sus últimas obras. Reacios a las nuevas tendencias y con el objetivo de demarcar claramente los espacios femeninos y masculinos, los articulistas se declaran contrarios al movimiento sufragista. Se afirma que las mujeres argentinas no están preparadas para esa responsabilidad y que, de todas maneras, cumplen una función primordial como pilares de la familia, organización básica de la sociedad : “...Aunque el Congreso de Sufragistas de Roma lo haya estatuido, la patria no necesita por el momento a las mujeres electoras, cuando ellas tienen en sus manos el gobierno de la familia, que a su vez es la patria bien organizada, invencible y feliz..." (Garrido De La Peña, Carlota, "Patriotismo de las mujeres", SG, nº 38, 31/05/1923, cifr Cristiá)

Desde aquí, Corazón Argentino cuenta, en primera persona, la historia de Ángel Revilla, hijo de un notable abogado, quien, desde su primer día de escuela está decidido a convertirse en un buen ciudadano. El libro combina lecciones morales con enseñanzas patrióticas, que se transmiten a través de las vivencias escolares o familiares del protagonista, pero también del "Cuento mensual", que éste escucha relatar en el aula cada mes en el aula, como tarea escolar. No obstante, son los pasajes del libro dedicados a Adela, hermana del niño, aquellos en que Carlota Garrido de la Peña retrata a la "madre del porvenir" de la que hablaba la advertencia. 
Así, Adela ejerce la caridad, como gran dama de su tiempo, al escoger como regalo de cumpleaños dar un banquete para sus compañeras de escuela pobres:

Antes de retirarse, la señorita Montaldo dijo a mamá:

-La felicito, señora. Entre las muchas cualidades de Adelita, atesora la de ser amable con los humildes. No sabe ella la popularidad que hoy se ha conquistado en doce hogares al mismo tiempo; esos hogares pobres que viven creyendo en el perpetuo desprecio del rico. Querida mía- dijo volviéndose a mi hermana, -sé siempre así, mira que Dios premia la bondad con los pequeños y los humildes. (Garrido de la Peña, 1921: 47)

La misma Adela se deja conmover e inspirar por la visita al asilo de los niños pobres en la que acompaña a su madre "La visita al Asilo había conmovido de seguro el corazón de mi hermana Adela, que, sin duda, estaba deseosa de ejercitar su caridad en algún ser desgraciado"(Garrido de la Peña, 1921: 92) o asume la voz de la "maternidad patriótica" cuando decide escribir a su hermano mayor que ha disgustado a sus padres al cambiar el estudio por la vida disoluta en la capital:

Todavía es tiempo de que recuperes las horas perdidas en malas distracciones. ¡Estudia, estudia con decisión, conquista tu título... y sigue las huellas de papá!... ¡Y luego ven a nuestros brazos, a los de mamá, rescatando tus faltas, animoso para vencerte en adelante y ser un hijo profundamente agradecido a sus desvelos, a sus consejos y a su amor!... (Garrido de la Peña, 1921: 103)

Por eso, cuando Ernesto es enviado a Buenos Aires a estudiar interno para convertirse en el ciudadano que de él se espera, Adela se queda en casa, es la única de los hermanos que no ha de marchar: "Esta tarde a las cinco abrazaré a mamá y a Adela, y no las volveré a ver hasta las vacaciones venideras" (Garrido de la Peña, 1921: 337)

Tantos los artículos como la ficción educacional de Corazón Argentino construyen un mismo ideal de mujer; pero ¿qué sucede con las heroínas de los relatos amorosos que escribe la misma autora?, ¿se ajustan a éste?

Reminiscencias (1888), publicado como un cuento largo, en formato de cuadernillo, cuenta la historia de Elena, hija de una familia notable argentina, en el momento de "ser presentada en sociedad". La joven ha acudido a buenos colegios por expreso deseo de se padre, pero desconoce el cortejo y la retórica amorosas. El primer deseo de su progenitor ha sido transformarla en una "mujer culta", sea para destinarla o no al matrimonio:

Eso no puede ser, no es posible, es preciso que te desprendas de ella, que me la entregues; y la Escuela Normal de señoritas, o si te acomoda a ti más, que en esto no me meto de Hermanas de la Caridad; te devolverá después una sobrina bonita, instruida, creyente hasta donde quieras; pero ¡culta! vive Dios, que es todo lo que 
yo quiero. Después ya se presentará un buen muchacho, eso sí tan rico como mi hija y de buena familia... y se la daremos... o no se la daremos, mujer. La dejaremos para que vista santos contigo si te empeñas. (Garrido de la Peña, 1888: 4)

Aunque éste es el destino que su padre le busca cuando, una vez termina el colegio, decide organizar una fiesta para dar a conocer a su hija, ya en edad casadera. A partir de este momento la joven se debate entre dos pretendientes de muy distinto signo: Héctor Reinals y Leopoldo Belgrano, amigos íntimos. El primero representa al joven voluble, que ansía una novia por fortuna, el segundo al ciudadano cabal. Elena acaba enamorada de Belgrano, amor e ideal de ciudadanía coinciden, la felicidad de la joven esposa es posible. Su familia jamás la presiona para que acepte uno $\mathrm{u}$ otro matrimonio.

No obstante, las historias de Cómo en la vida y Mar sin riberas son de muy distinto signo, pues amor/matrimonio se presentan como realidades divergentes, el designio social y la felicidad no van de la mano. En la primera de las novelitas se trabaja un tema muy original en la narrativa amorosa de la época: la irrefrenable atracción que una mujer virtuosa siente por un donjuán, siendo plenamente consciente de su error, el erotismo que despierta en la mujer se presenta como fuerza irresistible. Amelia, joven viuda, se enamora de Martos, vividor y seductor, ella conoce lo inoportuno de su elección, pero no puede refrenar la pasión que siente por él, aunque la reprime, cayendo en una depresión amorosa. Su primo Ángel, médico de profesión, acaba curando su mal al darle a conocer sus sentimientos virtuosos. Aunque el final es semejante al de Reminiscencias, lo interesante de esta obra es el retrato que se construye de la pasión de Amelia. Ésta cuenta con independencia económica como viuda adinerada, es inteligente y no se deja engañar por Martos, pero la atracción sexual que éste desprende la dejan atrapada. Raramente, una novela de la época habría de retratar con tal detalle y verosimilitud el deseo de una mujer.

Mar sin riberas, al igual que La familia del Comendador, puntúa el desajuste entre el querer ser/deber ser mujer. Gracia Gómez, joven criolla, que cree en el amor como condición para el matrimonio, será empujada por su madre a que se case Luis Guido, barón italiano, cónsul, en el que ve el candidato perfecto para su hija:

El amor, hija, ese amor de fantasmagoría, de exaltación y de romanticismo, sólo se halla en los libros... Sólo el matrimonio, una vez consumado, echa raíces profundas en el corazón y ata con un solo lazo, con una sola conveniencia y un solo interés a la mujer y al marido, haciendo que se comprendan y al fin se adoren. Yo tampoco me casé enamorada de tu padre (Garrido de la Peña, 1917?: 150)

Desde el momento en que acepte los consejos de su madre quedará apresada entre un matrimonio infeliz con un esposo vividor y en el amor hacia otro hombre, 
Julián Peña, que representa al ciudadano perfecto. La novela no sólo castiga al matrimonio que no se hace por amor, sino también la extranjería del esposo, Gracia era "Un tipo criollo adorable: uno de esos tipos que van siendo ya escasos en la masa popular como entre la gente de pro, gracias a las alianzas de las hijas del país con extranjeros" (Garrido de la Peña, 1917?: 105). Así, aunque sólo esbozada en el entrelineado de la trama, la historia patria preocupa a Carlota Garrido de la Peña, que denuncia la pérdida de símbolos como el gaucho, defiende las tradiciones criollas y critica duramente el exceso de "europeización" en el que ha caído el país.

De las tres autoras estudiadas es quien más se preocupa por producir "modelos de ciudadanía", como queda reflejado en Corazón argentino y sus artículos en prensa. Ahora bien, si éstos refuerzan la ideología de la novela nacional, también es cierto que, cuando nos adentramos en la obra de ficción podemos apreciar algunas resquebrajaduras, especialmente en lo que atañe a la representación de la mujer: capaz de desear, de gestionar su vida y su cuerpo, y de abordar de forma crítica ese "deber ser" que se le impone.

\section{Margarita Práxedes Múñoz: amor y ciencia}

Poco dice Clorinda Matto de esta autora: "Margarita Práxedes Muñoz, tiene publicados trabajos científicos sueltos y un libro con el título de La evolución de Paulina" (Matto de Turner, 1902: 256); pese a haber sido la primera mujer peruana que se licenció de medicina. Desconocemos con exactitud su fecha de nacimiento, aunque sería en torno a 1850 , en el seno de una familia limeña liberal y laicista. Obtuvo los estudios de Bachiller de Ciencias en Perú. En 1885 se marcha a vivir a Santiago de Chile, donde se licencia pocos años después.

Desde los comienzos de sus estudios la autora iría publicando diferentes ensayos sobre las grandes doctrinas científicas de su tiempo, colaborando asiduamente en presa. También opinaría en sus artículos de filosofía, política y el devenir del presente. Muy pronto se incorporó a las tertulias intelectuales de la ciudad de Santiago, donde conocerá la obra de Augusto Comte. Inspirada en ésta publica en 1893 la novela La evolución de Paulina.

En el año 1895 tendría que exiliarse a Buenos Aires, su pensamiento rotaría de la ortodoxia comtiana al feminismo librepensador. La teosofía y el cristianismo alternativo serían también corrientes de interés para ella.

La evolución de Paulina se nos presenta como una novela única en su género. A modo de una carta, escrita a su amiga Estela, la protagonista cuenta cómo desde niña siente una profunda inclinación al estudio y las ciencias:

Sólo sabías que un deseo único, ardiente y exclusivo enseñoreábase de mi pecho desde los albores de la razón: la investigación de la verdad. Sabías la lucha en que me había visto empeñada con mi familia, que no comprendía que un débil niña soñara engalanar sus sienes con los laureles de Minerva, patrimonio exclusivo del 
sexo fuerte, y no ignorabas cuán acribarada había sido mi existencia antes de alcanzar la satisfacción de mis legítimas aspiraciones. (Práxedes Muñoz 14)

Desde el momento en que logra su independencia, que pasa por dejar de lado cualquier supervisión masculina: "Dueña al fin de mi misma por la muerte de mi tutor, enteguéme por completo al estudio de mi ciencia predilecta" (Práxedes Muñoz 17), el estudio se convierte en motor de vida. Ahora bien, a diferencia de otras mujeres de su tiempo su interés no es la escritura, sino las ciencias naturales: "Muchas peruanas habían conquistado preciosos laureles en la carrera literaria; pero no se la había ocurrido a ninguna explorar el dilatado campo del saber. (Práxedes Muñoz 23).

A partir de la lectura de un artículo que le parece brillante se enamora de su autor, al que logra conocer en persona. Desde este momento, entre los dos jóvenes surge una profunda relación que combina amor y ciencia. No obstante, lo que parecería una solución idílica y trasgresora para el folletín "de género": una mujer entregada a su deseo, por un hombre y por una profesión, queda truncada por la inconstancia de él, que se cansa de su compañía y la abandona para seguir sus propios placeres.

Es entonces cuando se observa la desigualdad que la sociedad peruana ha construido para el hombre y la mujer; pues mientras Alberto viaja, es dueño de su tiempo, su fortuna y su destino, la protagonista carece de tal libertad de movimientos y su "deber ser" restringe sus actividades a la vida "privada".

Desde aquí, la novela tematiza las limitaciones de la mujer peruana:

La mujer peruana está reducida a la triste condición de la mujer rusa. Si abriga el legítimo deseo de conquistarse un nombre o una posición holgada en la sociedad, ya sea mediante el cultivo de las ciencias médicas o jurídicas, habrá de emigrar al extranjero y desterrarse del hermoso y purísimo cielo de la Patria, ¿Y así nuestro país aspira a ocupar un lugar entre las naciones cultas? (Práxedes Muñoz 24)

La segunda parte del texto es un ensayo sobre la filosofía comtiana, los títulos de los capítulos así lo atestiguan: "Noticia de Augusto Comte", "Principios fundamentales de la filosofía positivista", "Augusto Comte y la bilogía", "la Filosofía de la historia", "El positivismo religioso". La protagonista, desengañada porque entiende que es imposible conciliar el amor a un hombre con el amor a la ciencia, conoce al padre Esteban con quien debate sobre las materias de los capítulos. La evolución de Paulina es, ante todo, un ensayo, que exhibe las posibilidades de alta reflexión filosófica en la obra de una mujer.

Asimismo, de nuevo, como fondo o entrelineado de la obra emerge la reflexión por la patria, ahora sumida en una guerra absurda: "¡Cuántos hogares enlutados, cuánta sangre derramada, cuánta miseria! ¡Y todo va a ser inútil! La deplorable vanidad de un mandatario imprudente, que soñó a agitarse a expensas de la nación, 
es la ruina de nuestro Perú. (Práxedes Muñoz 13)". La novela defiende un pancontientalismo pacífico, una unión de países latinoamericanos, que acabe con guerras que se consideran estériles.

Sea como fuere, el texto de Práxedes Muñoz resulta revolucionario, puesto que utiliza el drama romántico para desestabilizar la imagen-mujer de la novela nacional de forma radical, denunciando las injusticias y desigualdades que esta ocasiona, demandando una profunda transformación, semejante a la que está teniendo lugar en otros países del continente. La extensa exposición filosófica sirve para respaldar esta petición: no sólo porque las ideas que allí se muestran la justifica, sino porque una mujer es capaz de articularlas y debatirlas.

\section{Cuando las obreras del pensamiento escriben de amor}

"Mujer sin dedal" o "redentora", "letraherida" o "madre letrada" la representación de las mujeres en la prensa decimonónica latinoamericana está plagada de contradicciones, aquellas que responden a un mundo en tránsito, que debe inventar nuevas estrategias de representación, pero que, a su vez, no puede renunciar a las viejas imágenes porque teme los cambios. En el juego de la figuración/invención nacional el papel que se otorga a la mujer implica un desafío, que la novela de folletín, como género popular de gran fuerza plástica, aborda sin complejos, proponiendo estrategias y resultados dispares.

Las "obreras del pensamiento" conocedoras del poder modelizante del género, pero también de sus numerosas lectoras, hicieron de éste un espacio de autorepresentación, exploración y fractura, desde el que emergerá, en ocasiones, un proto-feminismo, cargado de ambivalencias, pero también consciente de ser portador de una promesa.

Desde aquí, Juana Manso denuncia en La familia del Comendador los abusos que por razones de género o raza la sociedad de su tiempo comete sobre las mujeres; al tiempo que delinea un modelo de mujer que demanda la gestión de su vida y su deseo. Carlota Garrido de la Peña se debate entre la defensa de la "maternidad patriótica", trazada en Corazón argentino o Reminiscencias y los contra-modelos de Como en la vida y Mar sin riberas; al tiempo que Margarita Práxedes Muñoz revoluciona el género al convertir el folletín en un tratado de filosofía.

Desde proyectos dispares, con convicciones y titubeos, algunas de las "obreras del pensamiento", citadas por Matto de Turner se apropiaron de la tradición de la "novela nacional" desde el folletín, trazando un tradición propia "de género", que habría de constituirse en síntoma de las revoluciones por venir. 


\section{BIBLIOGRAFÍA}

ACOSTA DE SAMPER, Soledad.

1895 La mujer en la sociedad moderna. París: Garnier.

ARCos, Carol.

2010 "Novelas folletín y la autoría femenina en la segunda mitad del XIX en Chile", Revista Chilena de literatura, no 76, pp. 27-42.

BATTICUORE, Graciela.

1999 El taller de la escritora. Veladas literarias de Juana Manuela Gorriti: Lima- Buenos Aires (1876/7-1892). Buenos Aires: Beatriz Viterbo Editores.

CRISTIÁ, Moira.

2009 "Entre tradición e innovación. Representaciones femeninas en otra modernidad periférica (Rosario, 1922-1924)", Debates,

http://nuevomundo.revues.org/57686, fecha de última consulta 3/5/2013.

DENEGRI, Francesca.

1995 El abanico y la cigarrera. La primera generación de mujeres ilustradas en el Perú. Lima: IEP.

FERRÚS, Beatriz.

2011 Mujer y literatura de viajes en el siglo XIX: entre España y las Américas. Valencia: PUV.

2012 "¿Madres de la nación u obreras del pensamiento? Escritoras latinoamericanas y literatura sentimental en el siglo XIX", Quaderns de Filologia, vol.17.

2013a "Las "obreras del pensamiento" y la novela de folletín (Rosario Orrego de Uribe, Lastenia Larriva de Llona y Josefina Pelliza de Sagasta)", Lectora. Revista de Mujeres y Textualidad, $\mathrm{n}^{\circ}$ 17, pp.149-160.

2013b "Los libros misceláneos y la emergencia de la escritora profesional: Juana Manuela Gorriti y Clorinda Matto de Turner", Castilla. Estudios de Literatura, no 4 , pp.39-55.

FREDERICK, Bonnie.

1993 La pluma y la aguja. Buenos Aires: Feminaria.

1998 Wili Modesty. Argentine Women Writers, 1860-1910. Tempe: Arizona State University.

GARRIDO DE LA PEÑA, Carlota.

1888 Reminiscencias. USA: Paperback.

1917? Como en la vida/Mar sin riberas. Valencia: Prometeo.

1921 Corazón argentino: diario de un niño. Buenos Aires: Cabaut y Cía. MANSO, Juana.

2006 La familia del comendador. Buenos Aires, Biblioteca Nacional. 
MATTO DE TURNER, Clorinda.

1902 "Las obreras del pensamiento en la América del Sur”, en Boreales, miniaturas y porcelanas. Buenos Aires: Juan A. Alsina.

1909 Viaje de recreo. Valencia: Sempere.

PRATT, Mary Louise.

2000 "No me interrumpas: las mujeres y el ensayo latinoamericano", Debate feminista, en http://www.debatefeminista.com/articulos, fecha de última consulta 3/5/2013

PRÁXEDES MUÑOZ, Margarita.

1893 La evolución de Paulina: novella sociológica. USA: Ulan Press.

SARLO, Beatriz.

2011 El imperio de los sentimientos. Buenos Aires: Siglo XXI.

SERRANO DE WILSON, Emilia.

1890 América y sus mujeres, Barcelona, Fidel Giro.

1904 Mujeres ilustres de América. Bosquejos biográficos. Barcelona: Maucci.

SOMMER, Doris.

2004 Ficciones fundacionales. Las novelas nacionales de América Latina. México DF: FCE. 